\title{
Equatorial Atlantic Ocean dynamics in a coupled ocean-atmosphere model simulation
}

\author{
Emanuel Giarolla $^{1}$ - Leo San Pedro Siqueira ${ }^{2}$ - Marcus Jorge Bottino ${ }^{3}$. \\ Marta Malagutti $^{2} \cdot$ Vinicius Buscioli Capistrano ${ }^{2} \cdot$ Paulo Nobre $^{2}$
}

Received: 28 July 2014 / Accepted: 1 April 2015 /Published online: 19 April 2015

(C) The Author(s) 2015. This article is published with open access at Springerlink.com

\begin{abstract}
The ocean temperatures and zonal currents at the equatorial Atlantic simulated by an improved version of the Brazilian earth system model (BESM), with changes in the cloud cover scheme and optical properties of the atmospheric component, are analyzed and compared to those obtained from a previous version of BESM and also from other seven selected CMIP5 models. It is shown that this updated version of BESM, despite some persistent biases, more accurately represents the surface temperature variation at the Equator and the equatorial thermocline east-west slope. These improvements are associated to a more realistic seasonal cycle achieved for the Atlantic equatorial undercurrent, as well as sea surface temperatures and zonal wind stress. The better simulation of the equatorial undercurrent is, in its turn, credited to a more realistic representation of the surface wind position and strength at the tropical Atlantic by the coupled model. With many of the systematic errors noticed in the previous version of the model alleviated, this version of BESM can be considered as a useful tool for modelers involved in Atlantic variability studies.
\end{abstract}

Responsible Editor: Jin-Song von Storch

Emanuel Giarolla

emanuel.giarolla@cptec.inpe.br; egiarolla@yahoo.com.br

1 Center for Weather Forecast and Climate Studies - CPTEC, National Institute for Space Research - INPE, Avenida dos Astronautas 1758, São José dos Campos, SP, Brazil 12227-010

2 Center for Weather Forecast and Climate Studies - CPTEC, National Institute for Space Research - INPE, Rodovia Presidente Dutra, km 40 SP/RJ, Cachoeira Paulista, SP 12630-970, Brazil

3 Center for Monitoring and Early Warnings of Natural Disasters CEMADEN, Rodovia Presidente Dutra, km 40 SP/RJ, Cachoeira Paulista, SP 12630-970, Brazil
Keywords Coupled ocean-atmosphere models · Atlantic equatorial undercurrent - Atlantic equatorial thermocline . CMIP5 models

\section{Introduction}

Global coupled ocean-atmosphere (OA) models have been extensively used for climate studies in order to capture the feedback mechanisms between the atmosphere and the ocean, which could not be reproduced by atmosphere-only models (see, e.g., Nobre et al. 2012 and Wang et al. 2005). However, due to the complexity of these models, some issues that are hard to be addressed are commonly found. An example of a common problem found in coupled models is the sea surface temperature (SST) warm bias in the eastern equatorial Atlantic, as stated by Richter and Xie (2008). Such systematic errors are present in almost all models of the CMIP3 ("coupled model intercomparison project," phase 3), and are still noticed in a great part of the CMIP5 (idem, phase 5) coupled models (Richter et al. 2012). Basically, almost all models analyzed in those studies have a cold bias in the warm pool region, a warm bias over the eastern equatorial Atlantic, and many are unable to simulate the SST minimum around $10^{\circ} \mathrm{W}$. Such systematic errors of global coupled OA models over the tropical Atlantic have profound deleterious impacts on the representation of climate variations over the Atlantic basin, as documented by Nobre et al. (2013) and others. Figure 1, similar to that diagram used by Richter and Xie (2008) and Richter et al. (2012), but for a mean of 30 years of equatorial SST values, show that the first version of the coupled ocean-atmosphere of the Brazilian earth system model (BESM), a cooperative effort of many brazilian institutions (Nobre et al. 2013), is also unable to reproduce such minimum at $10^{\circ} \mathrm{W}$. Bottino (2013) investigated some biases in that version of the BESM, named 
Fig. 1 The mean ocean surface potential temperature along the longitudes, in the equatorial Atlantic, as simulated by the CTRL experiment (solid grey), and the NCCS experiment (dashed grey), and by seven chosen CMIP5 models (as indicated by the legend). The WOA09 mean annual distribution (black) is represented as well. Scale in Celsius

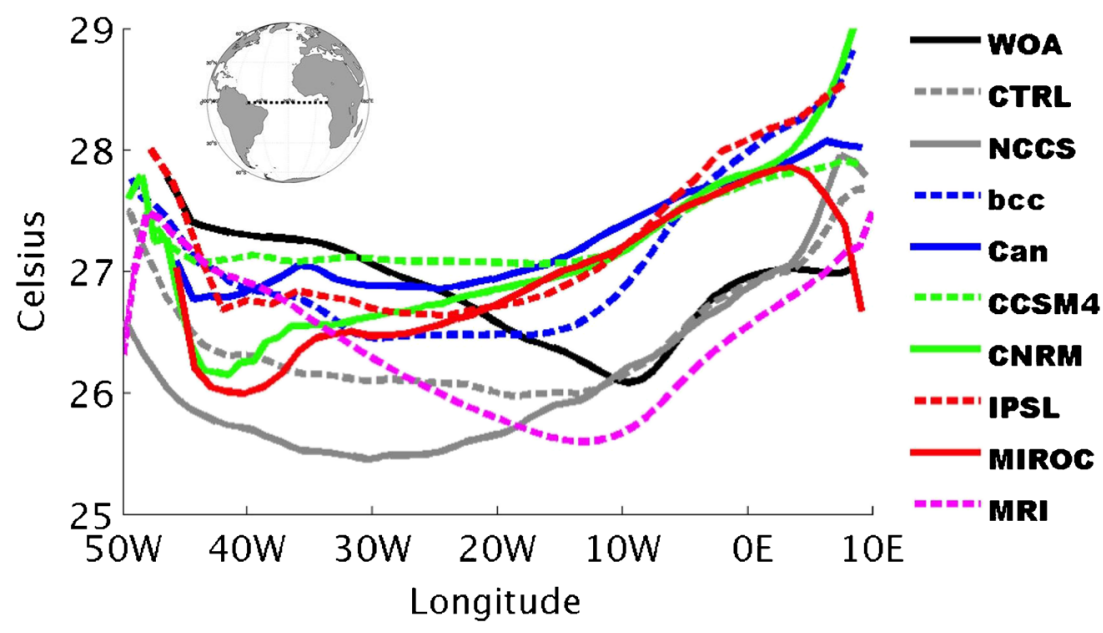

version OA2.3, which were part caused by systematic errors in the radiative fluxes, especially the radiative effects of cloud cover simulated by the atmospheric component of the model (an effect mentioned before in studies such as Cavalcanti et al. 2002). The BESM atmospheric model is a spectral model which has been developed since the 1990s at the Brazilian Center for Weather Forecast and Climate Studies/Brazilian National Institute for Space Research (acronym "CPTEC/ INPE"). The revision of the cloud cover scheme and other related parameterizations in the atmospheric component, described in Bottino (2013) and also in Bottino and Nobre (2015), resulted in a new version of the code. Their studies were focused on how the models represent the precipitation over the Atlantic intertropical convergence zone (ITCZ), and they noticed a remarkable improvement with the updated version (named BESM-OA2.3.1) in relation to that previous one (BESM-OA2.3). As a consequence, this new version of the model presented a SST zonal gradient with a closer resemblance to climatology, i.e., with a SST minimum nearer $10^{\circ}$ $\mathrm{W}$ than the one obtained by the previous version (Fig. 1). Also in Fig. 1, the SST patterns of seven other CMIP5 models are represented (more details about such models and experiments are given in the next section). Results vary substantially among the models. It is noticed that six of those models have the warm bias in the eastern equatorial Atlantic (east of $10^{\circ} \mathrm{W}$ ), one of them has a cold bias, while both versions of BESM have a better representation of the SST variation between $10^{\circ} \mathrm{W}$ and $5^{\circ} \mathrm{E}$, with a warm bias only at the easternmost region. The present study is focused on the subsurface changes in the equatorial Atlantic of version BESM-OA2.3.1, namely, the simulation of the thermocline depth at the equatorial Atlantic and the Atlantic equatorial undercurrent (EUC), in relation to version BESM-OA2.3. The thermocline commonly suffers from biases in coupled models especially in the eastern region, frequently due to biases in the precipitation and trade winds at the tropical Atlantic (see, e.g., Richter and Xie 2008). In this study, the Atlantic equatorial thermocline simulated by both versions of BESM, and by the other selected CMIP5 models, will be compared, to infer whether the new version of the model is able to alleviate such biases, since improvements were noticed in its outgoing longwave radiation and trade winds over the tropical Atlantic. Other reported mechanism for SST biases is a poor representation of the EUC, a subsurface current with a major role in the equatorial circulation since surface waters, which are subducted near $20^{\circ} \mathrm{N}$ and $20^{\circ} \mathrm{S}$ and move westward and equatorward, eventually reach the EUC and are carried eastward across the basin, providing cool and salty waters to central and eastern equatorial regions (Johns et al. 2014, and references therein). Due to its importance, in this study, the Atlantic EUC simulated by the models is investigated, through a comparison of its core mean depth and seasonal variability with observations provided by the prediction and research array of moored buoys over the Tropical Atlantic (PIRATA) project. The structure of this article is the following: section 2 describes the model and data sets used, section 3 presents the results, and the conclusions and discussions are presented in section 4 .

\section{Model and data sets}

The BESM-OA2.3 is described in Nobre et al. (2013), but a brief description is as follows.

The atmospheric general circulation model (AGCM), developed at CPTEC/INPE, currently has many possible configurations, but in this study, it was chosen the same as in Nobre et al. (2012), which adopted Eurelian dynamics with reduced grid. Other options selected include the "simplified simple biosphere (SSiB)" surface model (Xue et al. 1991), Mellor and Yamanda (1982) level 2 boundary layer diffusion, Anthes (1977) approach for gravity waves, deep and shallow convection schemes by Grell and Devenyi (2002) and Tiedtke (1984), respectively, short-wave radiation CLIRAD-SW-M (Tarasova et al. 2006; Chou and Suarez 1999), and longwave 
radiation as Harshvardhan and Corsetti (1984) and Harshvardhan et al. (1987). Regarding the carbon dioxide concentration, two sets of experiments are performed; in the first set, the concentration is fixed $370 \mathrm{ppm}$ for all runs and, in the second one, it changes with a Mauna Loa-like increasing rate. For the purpose of this study, the second set was chosen, in order to perform the sensitivity studies without any external source of variability. The AGCM resolution is the triangular truncation of spectral coefficients at wave number 62 , corresponding to a horizontal grid spacing of approximately $1.875^{\circ} \times 1.875^{\circ}$ at the Equator, and 28 sigma levels unevenly spaced in the vertical (T62L28). The interactions of clouds in the radiation schemes are established by the cloud cover scheme and the cloud optical properties scheme. The cloud cover scheme in version BESM-OA2.3 is based in the methodology proposed by Slingo (1987), with modifications of Kinter et al. (1997), which is the standard scheme when both KUO and GRELL deep convection schemes are used. The new cloud cover scheme proposed by Bottino and Nobre (2015) is also based in Slingo (1987), but with many improvements adapted from Collins et al. (2004). The cloud optical property scheme, in its turn, which in the original version was based in Kiehl et al. $(1996,1998)$, in the updated version BESM-OA2.3.1 has two aspects changed according to Collins et al. (2004): the cloud droplet effective radius over the ocean and the ice crystal size parameterization as a function of temperature. A detailed description of these changes can be found in Bottino (2013) and Bottino and Nobre (2015).

The oceanic component is the "Modular Ocean Model" version 4p1 ("MOM4p1"; Griffies 2009) from the Geophysical Fluid Dynamics Laboratory (GFDL). The zonal grid resolution is $1^{\circ}$ of longitude and the meridional grid spacing varies uniformly from $1 / 4^{\circ}$ of latitude in the tropical region (between the Equator and $10^{\circ}$ ) to $1^{\circ}$ at $45^{\circ}$ and to $2^{\circ}$ at $90^{\circ}$, in both hemispheres. The vertical resolution comprises 50 levels with a $10-\mathrm{m}$ resolution in the upper $220 \mathrm{~m}$, increasing gradually to about $370 \mathrm{~m}$ at deeper regions. The model spin-up was done in a manner similar to that of Nobre et al (2012) and Nobre et al (2013), starting from rest and using Levitus and Boyer (1994) climatology as the initial thermohaline structure. An "ocean solo" version of BESM ran for 13 years with climatological atmospheric forcing fields, and additionally for 58 years (19502007) with interannual fields from Large and Yeager (2009), except for river discharges and the sea ice forcings, which were maintained climatologically in both cases. The results of this ocean solo spin-up were used as the ocean initial state for the coupled model experiments starting at 2004-2005. The model settings are similar to the coordinated ocean-ice reference experiments (COREs) settings (Griffies et al. 2009) with some modifications for the

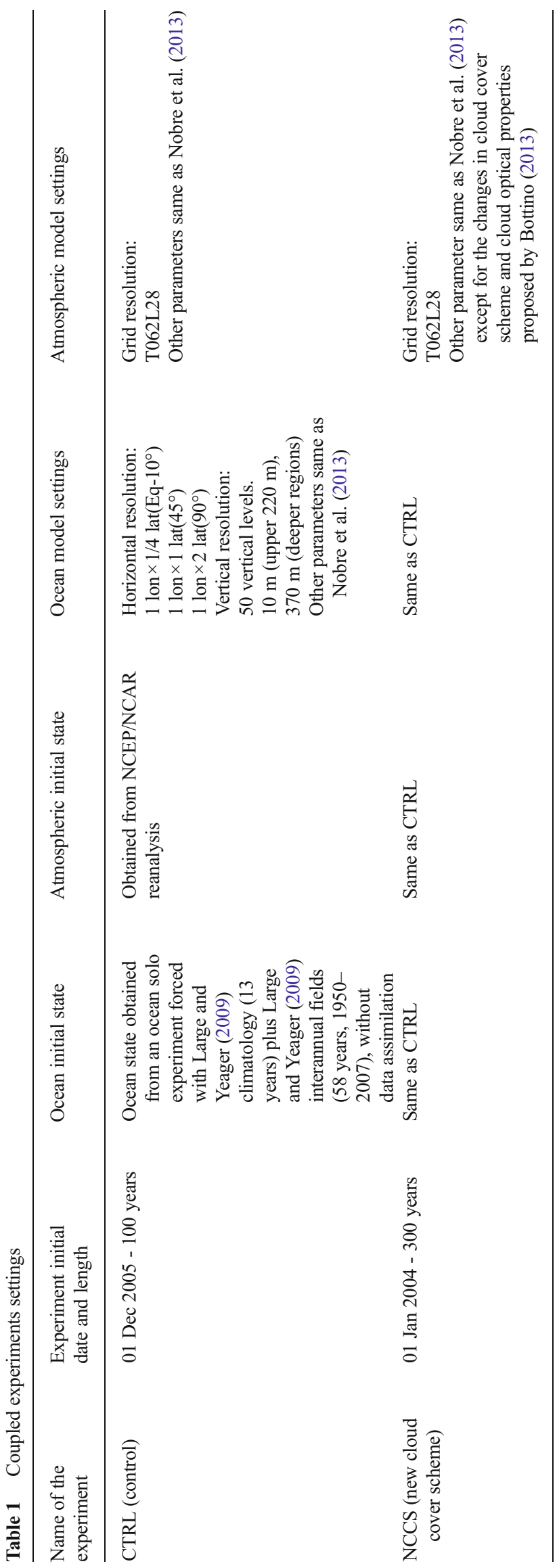


chosen ocean grid (Nobre et al. 2013). No ocean data assimilation was performed in the ocean solo and coupled experiments of BESM.

The coupling strategy includes the use of the GFDL's Flexible Modeling System (FMS) coupler to couple the CPTEC AGCM to GFDL MOM4p1 and the sea ice simulator ("SIS," Winton 2000). The AGCM receives SST and ocean albedo from the ocean and sea ice models at an hourly rate. The MOM4p1 in its turn, besides the winds at $10 \mathrm{~m}$, receives from the AGCM information about freshwater (liquid and solid precipitation), specific humidity, heat, vertical diffusion of velocity components and surface pressure, also at an hourly rate. Wind stress fields are computed using Monin-Obukhov scheme within MOM4p1. The hydrological cycle is balanced by an indirect method, as suggested in Griffies (2009). In the coupled model, the ocean temperature and salinity restorations are turned off.

Two sets of experiments were performed, a "control" set (hereafter CTRL), running the model with the same settings of the BESM-OA2.3 version, and the "new cloud cover scheme" set (hereafter NCCS), with the BESM-OA2.3.1 configuration, as shown in Table 1. The analysis were computed using monthly mean outputs of simulations with 100 or more years (Table 1), excluding the first 69 years for the coupled model to come into equilibrium and therefore avoiding possible climate drifts. As summarized in Table 2, the model results are compared to the climatological data from the world ocean atlas 2009 (Locarnini et al. 2010, hereafter "WOA09"), the acoustic Doppler current profiler (ADCP) dataset from the PIRATA project (Bourlès et al. 2008), the National Centers for Environmental Prediction/National Center for Atmospheric Research (NCEP/NCAR) atmospheric reanalysis (Kalnay et al. 1996), the extended reconstructed sea surface temperature V3b (ERSST, Smith et al. 2008), and the National Oceanic and Atmospheric Administration (NOAA) interpolated outgoing longwave radiation (Liebmann and Smith 1996). Seven CMIP5 models are selected to be compared with the two BESM experiments, with details shown in Table 3. The chosen experiment family was
"piControl" ("pre industrial control") because this family also has a constant carbon dioxide concentration, although with value usually lower $(280 \mathrm{ppm}$, for simulations starting in 1750 , as suggested by Stocker et al. 2013) than the one (370 ppm) used in CTRL and NCCS experiments.

For the BESM model, all analyses were performed using 360 months (years 70-99) of each CTRL and NCCS simulation. For the other CMIP5 models, the analyses also used 360 months, which were selected usually between years 70 and 99 in relation to the date of the first available file of each model, as shown in the last column of Table 3.

\section{Results}

One of the main improvements in the atmospheric component produced by the changes in the cloud optical properties scheme is the displacement of the convection, represented as the outgoing longwave radiation, from mostly over the tropical Atlantic Ocean (between $40^{\circ} \mathrm{W}$ and $10^{\circ} \mathrm{W}$ ), in Fig. $2 \mathrm{~b}$ for the CTRL simulation, to over land, in Fig. 2c for the NCCS experiment like in the observations (Fig. 2a). Although the NCCS captures the correct phase of the oceanic ITCZ during March-May (Fig. 2c), both CTRL and NCCS considerably underestimate the associated outgoing longwave radiation over land and place the core of the convection too far east over the East Africa highlands. The improvements in the ITCZ north-south migration and the displacement of the deep convection over land are expected to produce changes in the atmospheric zonal pressure gradient and consequently in the wind stress and "cold tongue" development (shown later in this section). Figure 3 shows the mean winds for experiments CTRL and NCCS over the Atlantic Ocean. It is observed in Fig. 3 that the ITCZ of the NCCS experiment shifts northward, while the South Atlantic subtropical high shifts eastward (Fig. 3b) in relation to the CTRL experiment (Fig. 3a). This configuration is in a better accordance with the NCEP/NCAR reanalysis (shading colors in both Fig. 3a and $b$ ). The RMSE latitudinal profile for each CTRL and NCCS experiments is shown in Fig. $3 \mathrm{c}$ and confirms that the

Table 2 Datasets used to evaluate model results

\begin{tabular}{|c|c|c|c|}
\hline Dataset & Variable(s) & Time period & Notes \\
\hline PIRATA ADCP data & $\begin{array}{l}\text { Zonal ocean currents at } 0^{\circ} \mathrm{N}, 23^{\circ} \mathrm{W} \\
\text { from } 0 \text { to } 140 \mathrm{~m} \text { depth }\end{array}$ & 2001-2009 & $\begin{array}{l}\text { There are many gaps in the period; } \\
\text { data are found mainly in } 2002 \text {, } \\
2004-2005 \text {, and } 2009\end{array}$ \\
\hline ERSST V3b & Sea surface temperature & 1980-2009 & - \\
\hline NCEP/NCAR reanalysis & Wind stress, surface winds & 1980-2009 & - \\
\hline NOAA & Outgoing longwave radiation & $1980-2009$ & - \\
\hline World ocean atlas 2009 & Ocean temperature & Climatology & - \\
\hline
\end{tabular}




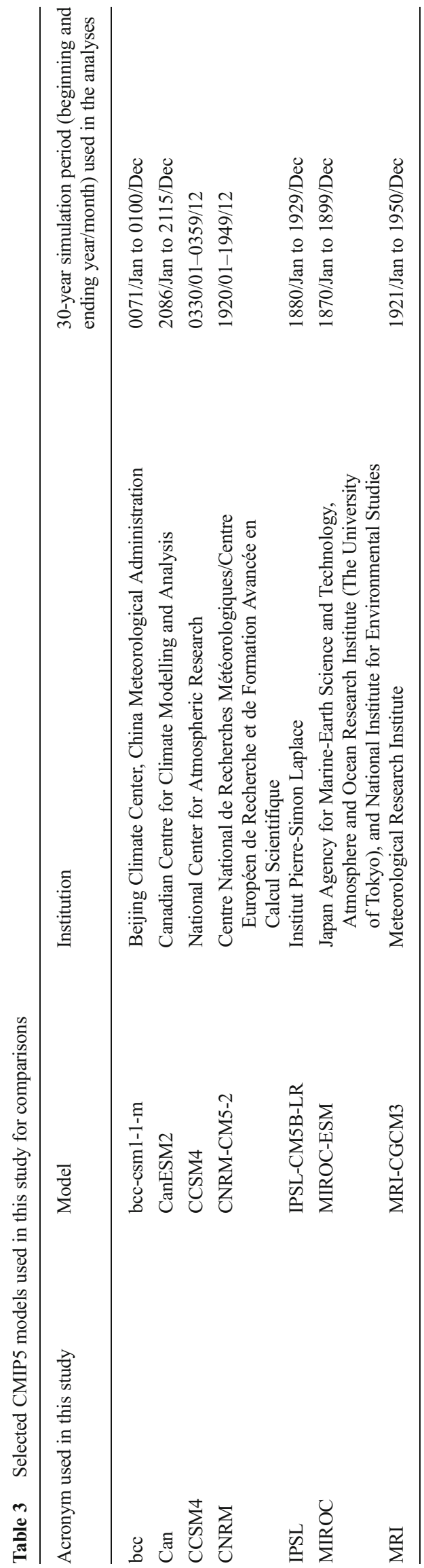

NCCS experiment has a better resemblance (i.e., presents lower RMSE) with respect to reanalysis.

The cold tongue, a common feature occurring seasonally in the tropical Atlantic, is the intrusion of relatively colder waters over the middle and the eastern part of the basin (see, e.g., Richter et al. 2012 and references therein). The seasonal variations of SST at $0^{\circ} \mathrm{N}, 10^{\circ} \mathrm{W}$ is shown in Fig. 4. The cold tongue is represented in the climatological temperature time series (black line) as the minimum between July and August. As opposed to the CTRL experiment (solid grey line), which fails to simulate the cold tongue, the NCSS experiment reproduces it, although with a phase shift between 1 and 2 months (dashed grey line). Yet, it is clearly noticed in Fig. 4a that both BESM versions present a warm bias during the cold tongue period. It is noteworthy that both a warm bias and a phase shift are also present in all but one of the CMIP5 models depicted in Fig. 4b. After comparing the experiment results at surface, it is instructive to see how they simulate the subsurface temperature structure, i.e., the equatorial thermocline zonal slope.

Figure 5a shows the annually averaged depth of the $20^{\circ} \mathrm{C}$ isotherm for both CTRL and NCCS experiments at the equatorial Atlantic. This isotherm is chosen because it is commonly used to define the thermocline depth in the equatorial Pacific, although not so accurately in some circumstances (Yang and Wang 2009). At the eastern part of the equatorial Atlantic, the NCCS thermocline is about 50-60 m deeper than the observed climatology, also deeper than the CTRL thermocline. Consequently, the root mean square error is 1.5-2 times higher for the NCCS experiment in comparison to the CTRL experiment in the region east of $20^{\circ} \mathrm{W}$ (Fig. 5c). However, in this same region, NCCS better represents the "shape" of the climatological thermocline slope, such as a relative depth minimum at approximately $5^{\circ} \mathrm{W}$, as seen in Fig. 5a, while the CTRL thermocline slope is flat. Regarding the other CMIP5 models counterpart (Fig. 5b), Can and MRI, as occurred to NCCS experiment, have a good representation of the thermocline slope at the eastern Atlantic, including the depth minimum at $5^{\circ} \mathrm{W}$, but at depths about 10 and $20 \mathrm{~m}$ deeper, respectively. Based on the root mean square error plot (Fig. 5d), the models that better represent the mean equatorial thermocline, east of $10^{\circ} \mathrm{W}$, are MIROC, CCSM4, and bcc.

Besides the thermocline depth, subsurface currents like the EUC also provide valuable information about the dynamics under the surface, as they may play important roles in the equatorial mass and heat exchange (see, e.g., Izumo 2005). Figure 6 depicts the mean seasonal variation of the equatorial Atlantic zonal current in a time-depth diagram at approximately $0^{\circ} \mathrm{N}, 23^{\circ} \mathrm{W}$, coincident with observed current data from the PIRATA ADCP site (Bourlès et al. 2008). It is shown that both CTRL (Fig. 6a) and NCCS (Fig. 6b) simulations reproduce the seasonal depth migration of the EUC core, despite a deeper than observed EUC simulation, in both experiments, during March-April. Apart from this bias, other 
(a) OBS

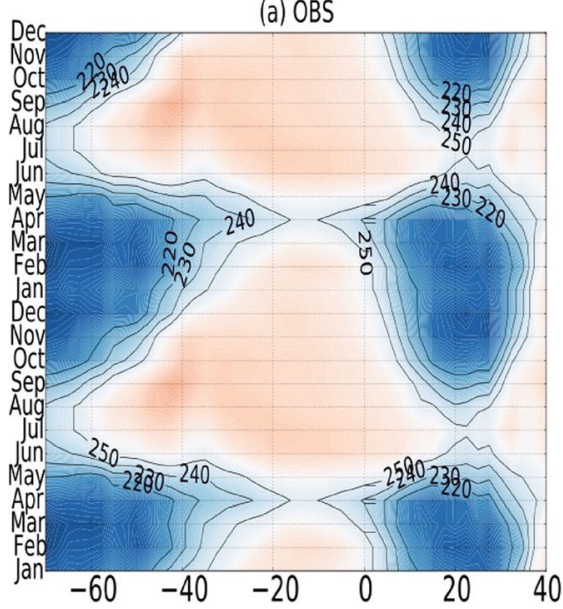

(b) CTRL

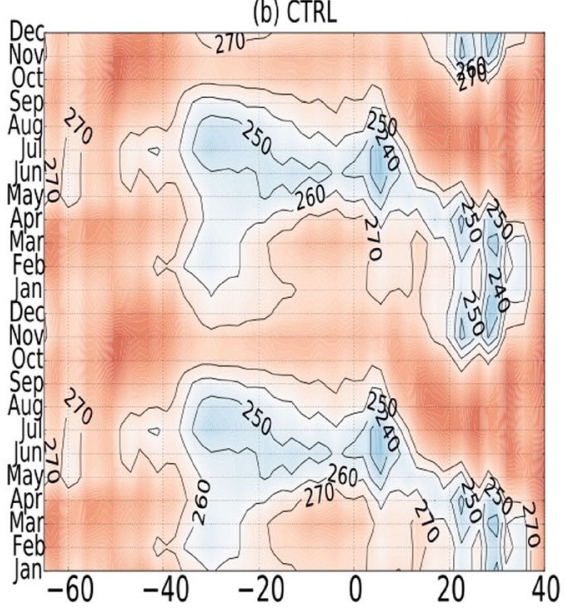

(c) NCCS

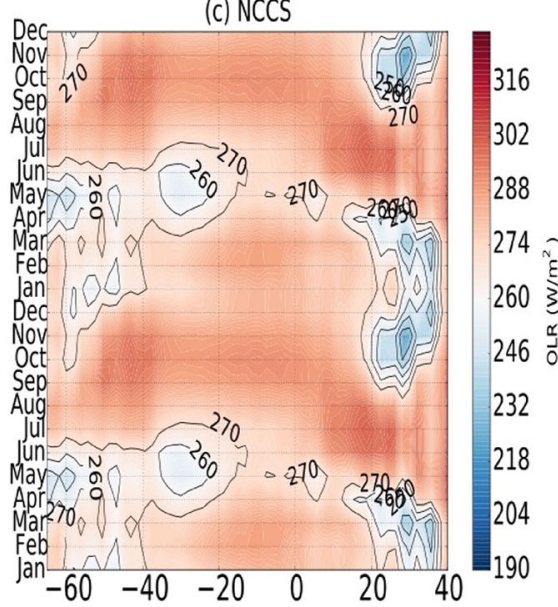

Fig. 2 Seasonal cycle (longitude-time) Hovmöller diagrams for outgoing longwave radiation at the equatorial Atlantic $\left(5^{\circ} \mathrm{S}-5^{\circ} \mathrm{N}\right)$ for $\mathbf{a}$ observed data, $\mathbf{b}$ CTRL, and $\mathbf{c}$ NCCS experiments. Contours in Watts per meter squared

features of the simulations show that the NCCS experiment better represents the zonal current profile at $0^{\circ} \mathrm{N}, 23^{\circ} \mathrm{W}$, as described below. In the CTRL experiment, there is an anomalous intrusion of westward (negative) currents from the bottom, from March to mid-August, at depths from 100 to $150 \mathrm{~m}$ approximately (Fig. 6a). Such erroneous characteristic is almost absent in the NCCS simulation. Both CTRL and NCCS experiments do not precisely represent the surfacing of the EUC, which is observed to occur between mid-March to April according to PIRATA data (shading colors in all diagrams of Fig. 6). In the CTRL simulation, the surfacing of eastward flow starts earlier, during the beginning of March, while in NCCS experiment, the surfacing happens after midApril. Nevertheless, the time period of the observed EUC surfacing, about 1.5 months, although not reproduced by any of those versions of BESM, is smaller in the NCCS than in the CTRL experiment, which lasts for more than 4 months. Previous studies such as Giarolla et al. (2005) showed that the surfacing of the Atlantic EUC is related to the weakening of the local winds. For the other CMIP5 models, the mean seasonal solution for the zonal current profile at $0^{\circ} \mathrm{N}, 23^{\circ} \mathrm{W}$ vary from model to model. Every model has features in agreement and discordance when compared to the PIRATA observations. A remarkable anomalous intrusion of westward currents from the bottom, as in BESM CTRL experiment, is observed in models bcc, Can, CNRM, and IPSL (Fig. 6c, d, f, g, respectively). The CCSM4 presents the best simulation of the EUC core magnitude (about $0.8 \mathrm{~m} \mathrm{~s}^{-1}$ or more), depth and seasonal variation (Fig. 6e), though it has an EUC surfacing that initiates too early (beginning of March) and lasts too long (until beginning of June), instead of the observed period mentioned above. On the other hand, IPSL and MIROC have the most realistic EUC surfacing (Fig. 6g, h).

The observed annual march of zonal wind stress can account for many of the observed features of the annual march in the thermal structure in the eastern-central equatorial Atlantic. Therefore, it is worth analyzing, in somewhat more detail the annual march of zonal wind stress on the Equator and (a)

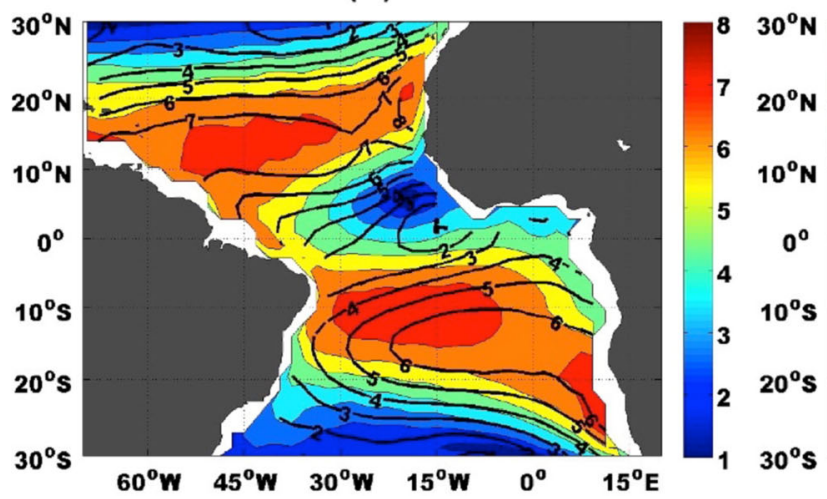

Fig. 3 Mean annual surface wind magnitudes, for a CTRL (contours) and b NCCS (contours) experiments, averaged between years 70 and 99, and for NCEP/NCAR reanalysis, averaged between 1980 and 2009 (shading colors in both maps). The zonally averaged RMSE between (b)

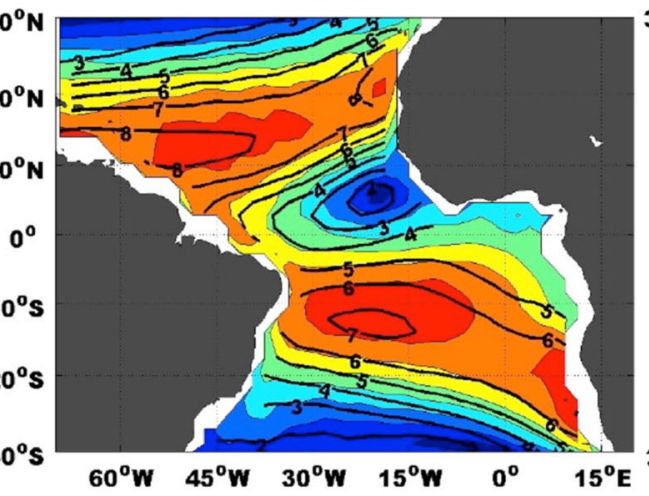

(c)

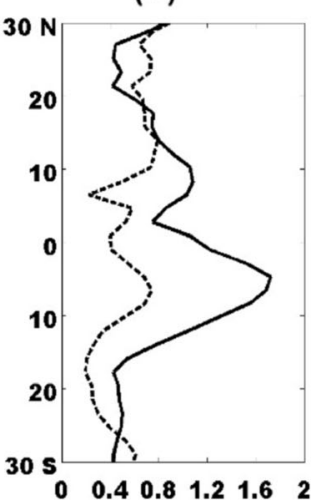

model and NCEP/NCAR wind magnitudes, at each latitude, is represented in $\mathbf{c}$, where the solid and dashed time series are related to CTRL and NCCS experiments, respectively. Values in meters per second 


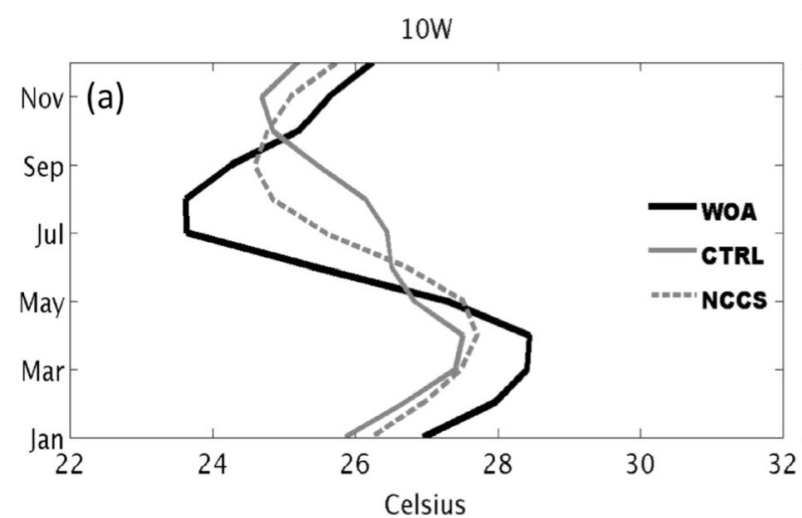

Fig. 4 Time series of surface potential temperature values at approximately $0^{\circ} \mathrm{N}, 10^{\circ} \mathrm{W}$, for WOA09 seasonal climatology (black line), for the respective climatologies of experiments CTRL (solid

meridional wind stress over the eastern basin and its possible role in accounting for the SST and EUC variations. Figure 7 shows the seasonal cycle in the deviations of sea surface temperature (shading) and wind stress (arrows) over the equatorial Atlantic $\left(5^{\circ} \mathrm{S}-5^{\circ} \mathrm{N}\right)$. As seen in Fig. 7 , both models simulate a seasonal weakening of the easterlies over $0^{\circ} \mathrm{N}, 23^{\circ} \mathrm{W}$, shown as deviations from the annual mean zonal wind stress, which are in fact correlated to the surfacing of the current in Fig. 6.
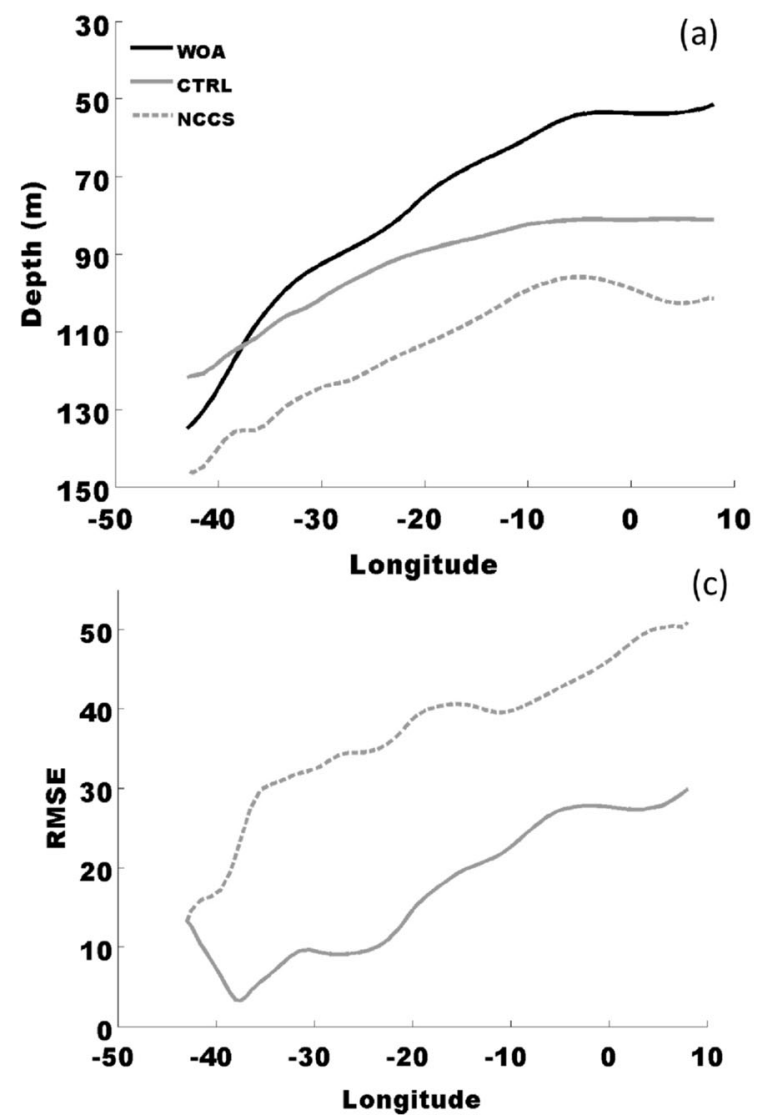

Fig. 5 a Annual mean depth of the $20{ }^{\circ} \mathrm{C}$ isotherm, along the Equator and at the Atlantic Ocean, for WOA09 climatology (solid black), CTRL (solid grey) and NCCS (dashed grey) experiments climatology, and $\mathbf{b}$ the

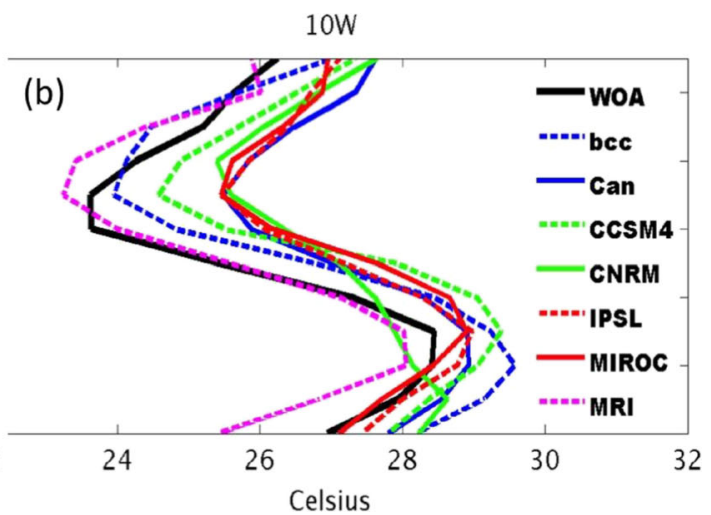

grey), NCCS (dashed grey), and for the climatologies of the chosen CMIP5 models (as indicated by the legend)

Figure 7a shows weak easterlies lasting from February to April over $0^{\circ} \mathrm{N} 23^{\circ} \mathrm{W}$ in the observations, while the CTRL (Fig. 7b) shows strong deviations in the easterlies that start in March and peak in June lasting about 5 months total. The variation in observed SST (Fig. 7a) is dominated by the annual harmonic that peaks around $0^{\circ} \mathrm{W}$, with the warm phase in March-April and the cold phase in August. The bulk seasonal variation in equatorial SST is realistically located over $0^{\circ} \mathrm{W}$ in
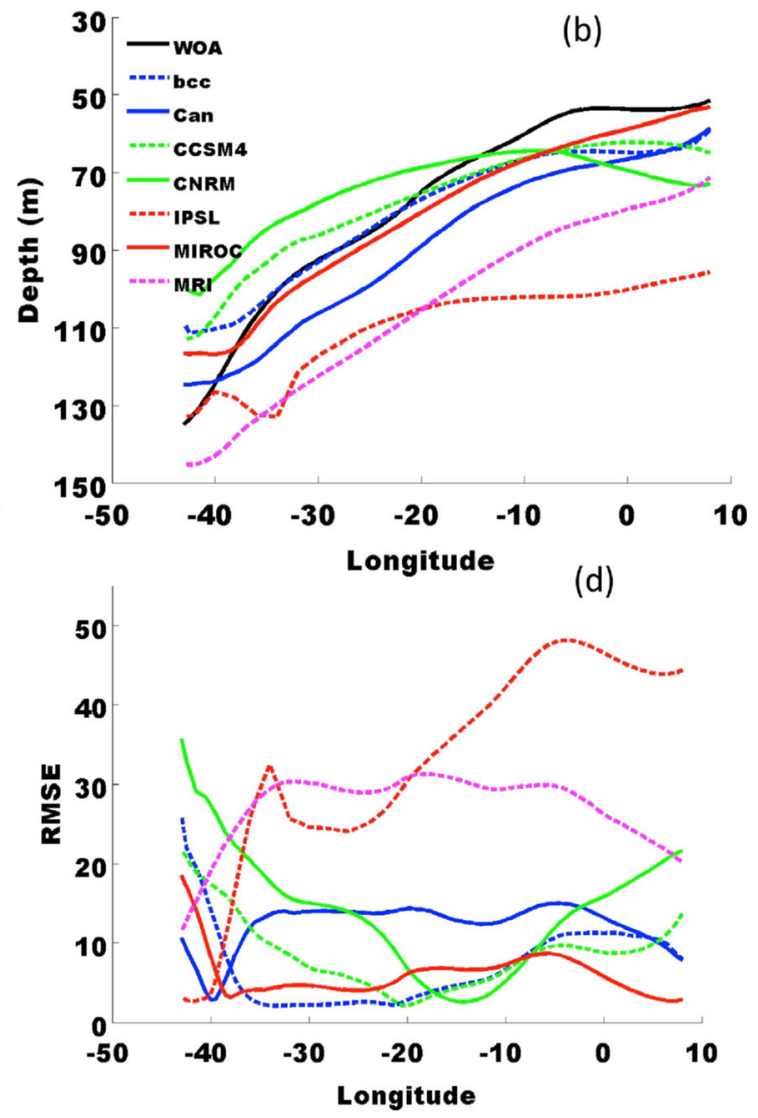

counterpart for the chosen CMIP5 models (as indicated by the legend), and the root mean square error between WOA09 and a CTRL and NCCS experiments and $\mathbf{b}$ other CMIP5 models experiments, with same legends 
(a) ctrL

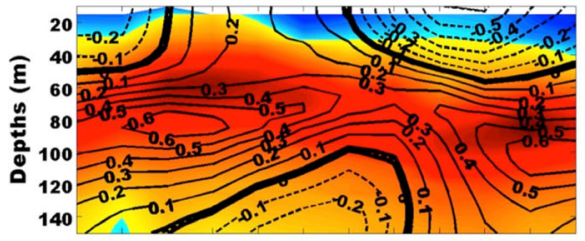

Jan Feb Mar Apr May Jun Jul Aug Sep Oct Nov Dec

(d) can

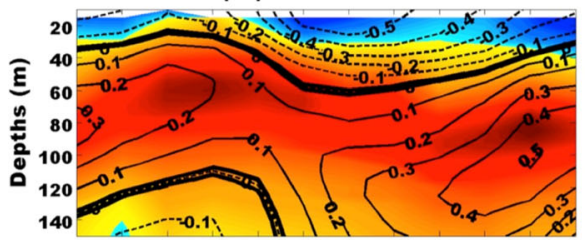

Jan Feb Mar Apr May Jun Jul Aug Sep Oct Nov Dec (g) IPSL

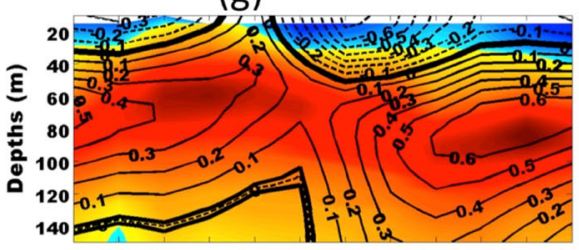

Jan Feb Mar Apr May Jun Jul Aug Sep Oct Nov Dec Months (b) nccs

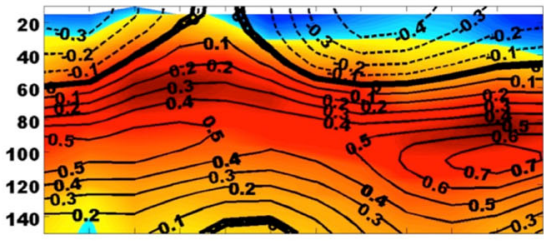

(e) $\cos 4$

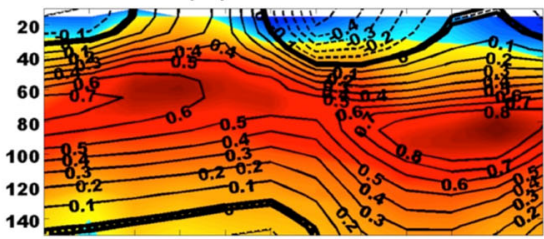

Jan Feb Mar Apr May Jun Jul Aug Sep Oct Nov Dec (h) Miroc

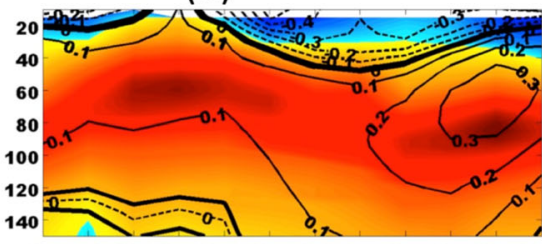

Jan Feb Mar Apr May Jun Jul Aug Sep Oct Nov Dec Months (c) bcc

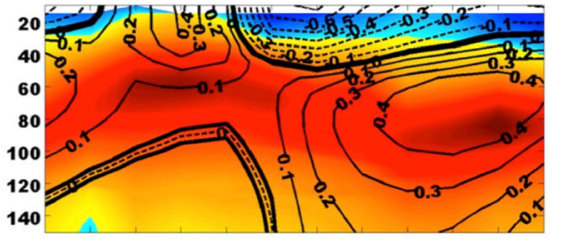

(f) CNRM

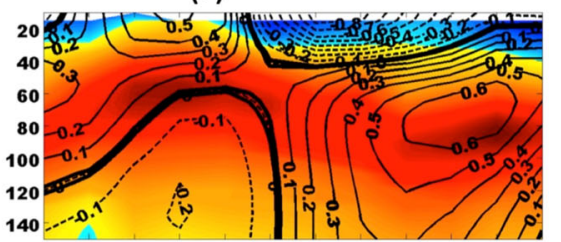

Jan Feb Mar Apr May Jun Jul Aug Sep Oct Nov Dec (i) $\mathrm{mRI}$

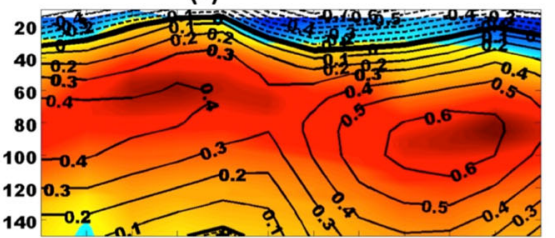

mat 740.2 act Months

\section{$\begin{array}{lllllll}-0.4 & -0.2 & 0 & 0.2 & 0.4 & 0.6 & 0.8\end{array}$}

Fig. 6 Time-depth diagrams of seasonal zonal current at $0^{\circ} \mathrm{N}, 23^{\circ} \mathrm{W}$ (in $\mathrm{m} \mathrm{s}^{-1}$ ). Contours represent a CTRL and $\mathbf{b}$ NCCS experiments, and the CMIP5 models c bcc, $\mathbf{d}$ Can, e CCSM4, f CNRM, g IPSL, h MIROC, and i MRI. The shading colors in $\mathbf{a}-\mathbf{i}$ diagrams were obtained from available records of the PIRATA ADCP, from 2002 to 2009 (a) OBS

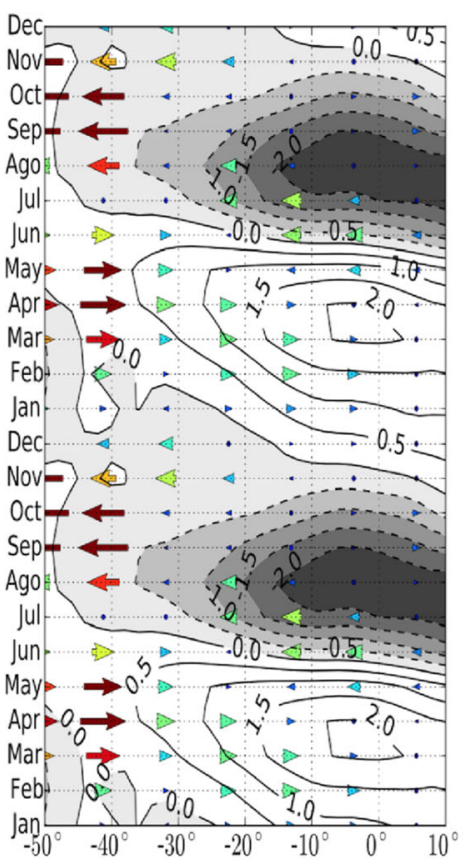

(b) CTRL

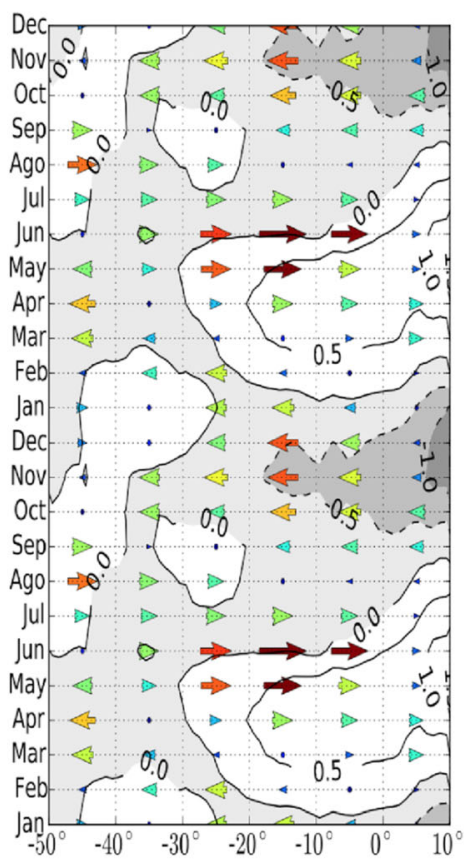

(c) NCCS

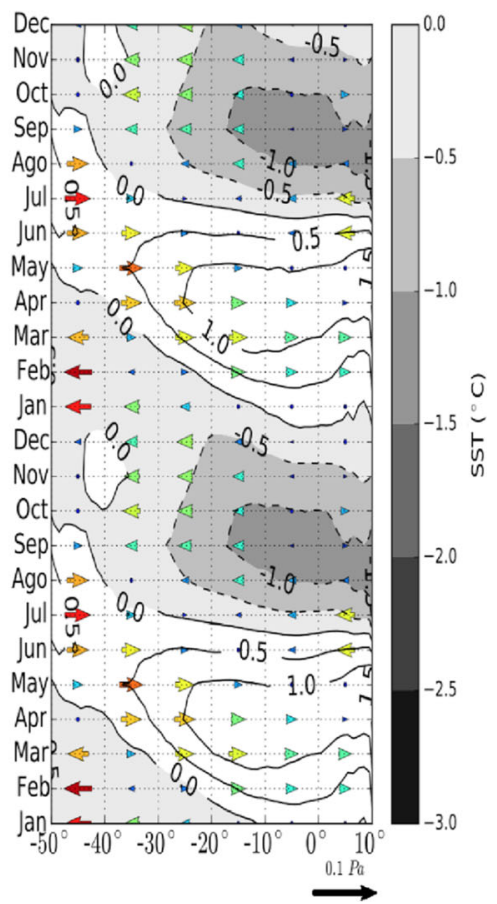

Fig. 7 Seasonal cycle (longitude-time) Hovmöller diagrams of equatorial Atlantic $\left(5^{\circ} \mathrm{S}-5^{\circ} \mathrm{N}\right)$ sea surface temperature in terms of deviations from the respective annual mean (shading) and deviations from the respective annual mean zonal wind stress (arrows), for a observed data (1980-2009) and b CTRL and c NCCS experiments results averaged between years 70 and 99 
the NCCS experiment (Fig. 7c) while it is concentrated too close the eastern coast in the CTRL run (Fig. 7b). The amplitude of the seasonal cycle is considerably weak in both experiments with a strong phase lag in the CTRL run, which shows the cold phase peaking in November-December while for the NCCS it peaks in September, which is nearer to the observations. The observed tendency for the seasonal cycle in SST to propagate westward is captured by the NCCS, whereas it erroneously propagates eastward in the CTRL experiment.

Figure 8 shows corresponding results for meridional wind stress (total field not deviations) and the SST deviations from the annual cycle over the eastern tropical Atlantic. The displacement of the African monsoon convection from the equatorial belt into the northern hemisphere during JulySeptember produces an increased northward flow that occurs in response to an increased northward-directed pressure gradient force. This intensification occurs simultaneously with the decrease in SST over the south and along the coast in the observations (Fig. 8a) that quickly expand westward throughout the equatorial Atlantic about a month later (Fig. 7a). The CTRL simulation (Fig. 8b) shows a considerably weak meridional wind stress throughout the year and a 3-month lagged cooling over $0^{\circ} \mathrm{N}$, although the increase in northward flow also starts in July. The NCCS experiment (Fig. 8c) shows a somewhat stronger meridional wind stress throughout the year than the CTRL run, and the intensification occurs simultaneously with the decrease in SST over the south and along the coast much like in the observations. The westward expansion of cold SST also occurs like in the observation but at a slower rate (Fig. 7c). Although the NCCS shows the strongest meridional wind stress during July-August, the cooling still lags for about a month compared to the observations, possibly due to the deeper thermocline, and it does not develop the Guinea SST minimum around $4^{\circ}-5^{\circ} \mathrm{N}$ during July-August.

An overall analysis of Fig. 6 shows that the EUC core depth varies among the models, a fact that is also supported in Fig. 9, which shows mean zonal current vertical profile at $0^{\circ}$ $\mathrm{N}, 23^{\circ} \mathrm{W}$. None of the BESM experiments reach the maximum observed value, around $0.75 \mathrm{~m} \mathrm{~s}^{-1}$ and approximately $80 \mathrm{~m}$ deep. While the CTRL EUC core is placed approximately at the right depth, the NCCS core is deeper (Fig. 9a). Apart from this, a RMSE analysis shows that both experiments have the maximum error at depths around $55 \mathrm{~m}$ (Fig. 9c), higher for NCCS. On the other hand, deeper than $80 \mathrm{~m}$, the NCCS error in the zonal currents is considerably lower than the CTRL experiment. In Fig. 9b, none of the other CMIP5 models could simulate the mean maximum magnitude of the PIRATA data (about $0.78 \mathrm{~m} \mathrm{~s}^{-1}$ ). The closer value was obtained by CCSM4, as already mentioned in the discussion of Fig. 6. The mean zonal current maxima of models MRI, IPSL, and Can, although much weaker, reach approximately the PIRATAobserved depth. The root mean square error plot (Fig. 9d) reflects the discrepancies between models and observations for the

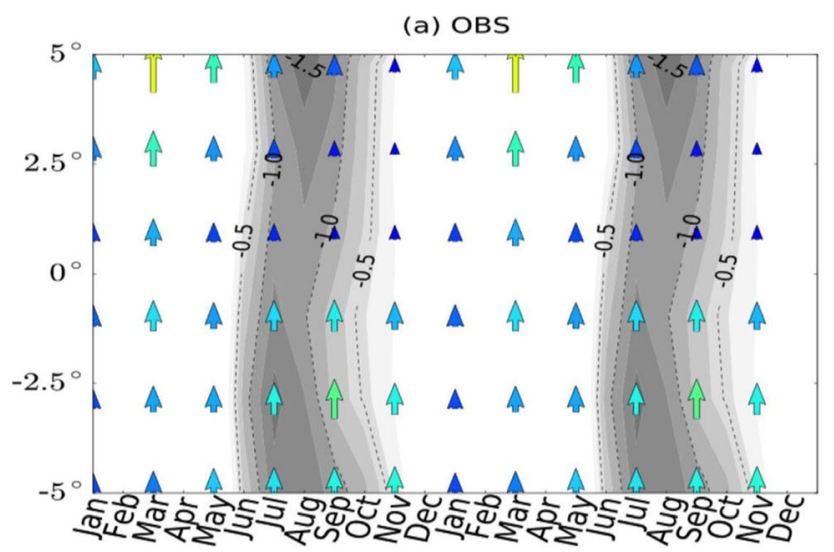

(b) CTRL

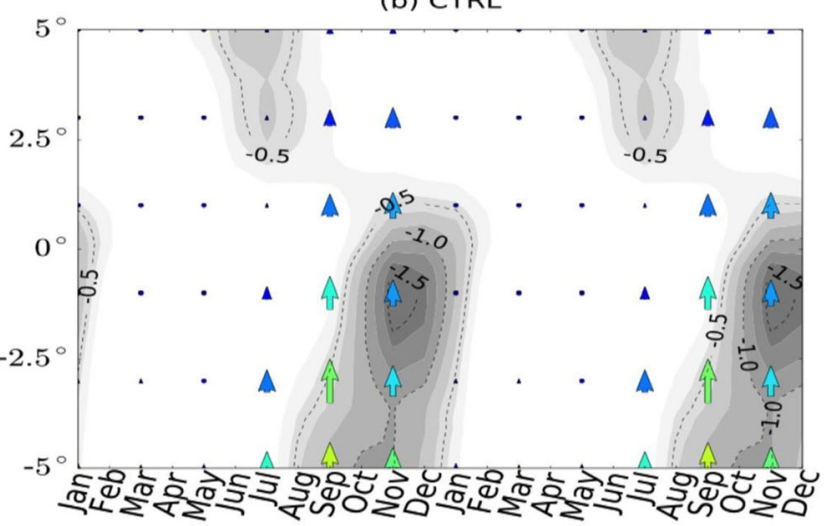

(c) NCCS

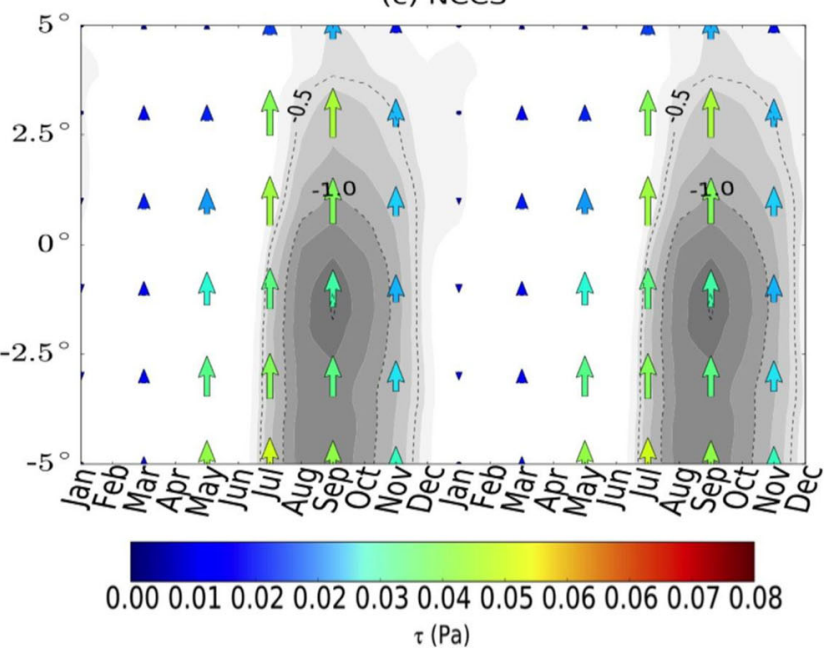

Fig. 8 Seasonal cycle (latitude-time section) of zonal mean sea surface temperature in terms of deviations from the respective annual mean (shading) and meridional wind stress (arrows) over the "eastern" sector $\left(20^{\circ} \mathrm{W}-10^{\circ} \mathrm{E}\right)$, for a observed data (1980-2009), and b CTRL and c NCCS experiments results averaged between years 70 and 99. Color bar represents magnitude of the meridional wind stress in $\mathrm{Pa}$

mean EUC core depth and magnitude, so the CCSM4 and MIROC models obtained the minimum and maximum errors, respectively. In the region deeper than the current maximum, a good agreement with PIRATA is noticed for NCCS and MRI 

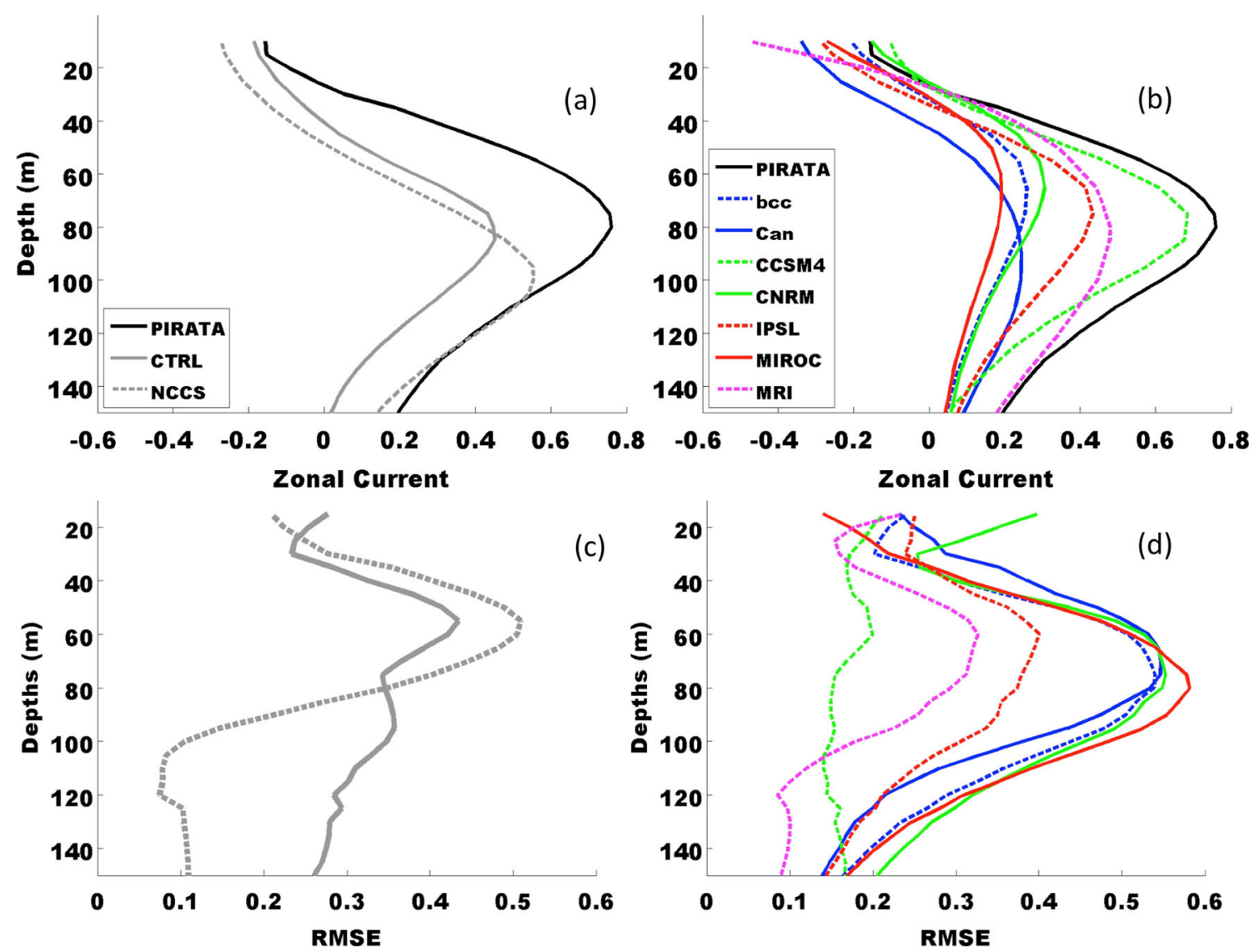

Fig. 9 (a) Mean zonal current at $0^{\circ} \mathrm{N}, 23^{\circ} \mathrm{W}$. The solid black line represents PIRATA ADCP. The other lines represent the CTRL (solid grey) and NCCS experiments (dashed grey), and (b) the other CMIP5

models (as indicated by the legend) in $\mathrm{m} \mathrm{s}^{-1}$, and the root mean square errors along depths computed between PIRATA and (a) model results for CTRL, NCCS and (b) other CMIP5 models (same legends)

model, resulting in lower root mean square errors, with values around 0.1, in Fig. 9c, d.

\section{Summary and discussion}

The changes in the cloud cover scheme and optical properties of the BESM-OA2.3 brought improvements in the atmospheric circulation over the tropical Atlantic, as discussed by Bottino (2013) and Bottino and Nobre (2015), summarized in this study as the more realistic simulation by the new version BESM-OA2.3.1 of the outgoing longwave radiation at the equatorial Atlantic (Fig. 2), followed by a better representation of the mean position of the ITCZ in the tropical Atlantic (Fig. 3) and wind stress components along the Equator (Figs. 7 and 8). These atmospheric changes allowed the ocean component of the new version to represent the SST seasonal cycle along the Equator (Figs. 7 and 8) and the cold tongue (Fig. 4) better, in comparison to the previous model version. Improvements were also noticed in subsurface features, such as a more appropriate representation of the thermocline slope and seasonal variation of the $\mathrm{EUC}$ at $0^{\circ} \mathrm{N}, 23^{\circ} \mathrm{W}$ by the new version; however, in both versions, the overall thermocline

position (Fig. 5) and EUC seasonal maxima (Fig. 6) were placed at deeper depths than observation.

The relation between thermocline and EUC core depth has already been discussed in other studies, e.g., Yin and Sarachik (1993). About the heat balance which maintains the EUC, Yin and Sarachik (1993) state that the heat balance in the EUC core is a result of zonal and vertical advection, so heat diffusion is the residual of advective heat transport, suggesting that the EUC core cannot exist far away from the thermocline. They also state that the relative position of the undercurrent core is above the thermocline if the net heat advection balance tends toward heating. This seems to be the case for both simulations, as seen in Fig. 10 with the mean EUC core and thermocline along the Equator represented. The NCCS experiment has a more zonally extended and stronger EUC, which is more realistic when compared to observational studies such as Johns et al. (2014) but, still, both weaker and deeper than the observed counterpart, as revealed by the following discussion.

Equatorial easterlies are commonly weak in coupled models (Richter and Xie 2008). In fact, the difference between the annual mean winds of NCEP/NCAR reanalysis and BESM experiments, shown in Fig. 3a, b, lies between 3-4 
(a)

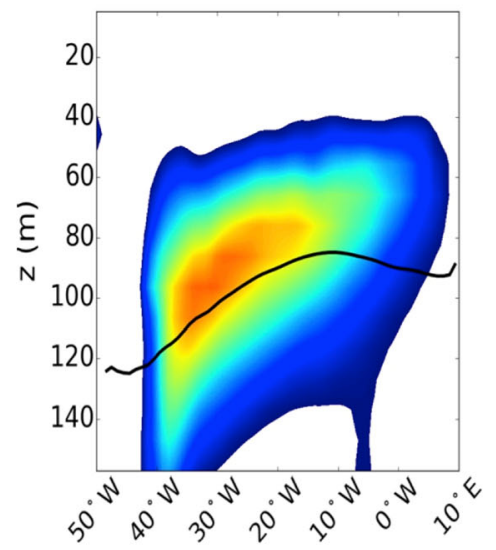

(b)

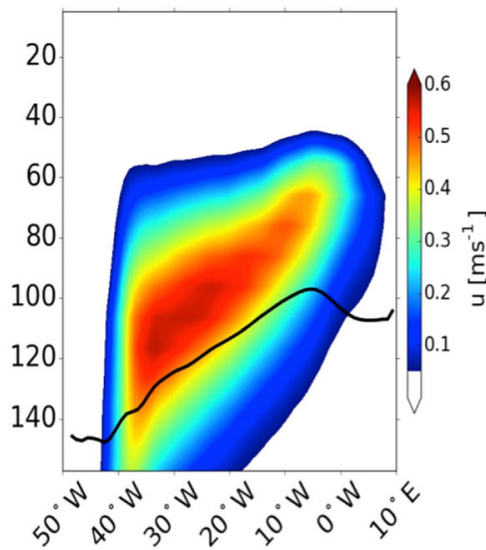

(c)

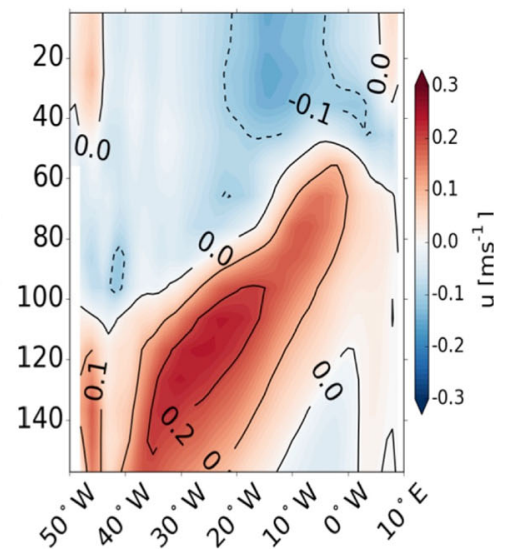

Fig. 10 Mean of the zonal current profile at the equatorial Atlantic, for (a) CTRL and (b) NCCS experiments (only positive values drawn), and (c) the difference between NCCS and CTRL. Values in $\mathrm{m} \mathrm{s}^{-1}$. The black line in (a) and (b) represents the $20^{\circ}$ isotherm

and $1-1.5 \mathrm{~m} \mathrm{~s}^{-1}$, for CTRL and NCCS experiments, respectively, in the tropical Atlantic (figure not shown). Weak easterlies result in weak upwelling, an excessively deep thermocline in the central and eastern parts of the Atlantic and, consequently, warm SST bias in that region (Johns et al. 2014, and references therein). But, Johns et al. (2014) also mention that the EUC simulated by coupled models is normally weaker, or less extensive zonally, than the observed one. As a consequence, the strong shear between the EUC and the upper opposite currents, which drives strong vertical mixing and (a)

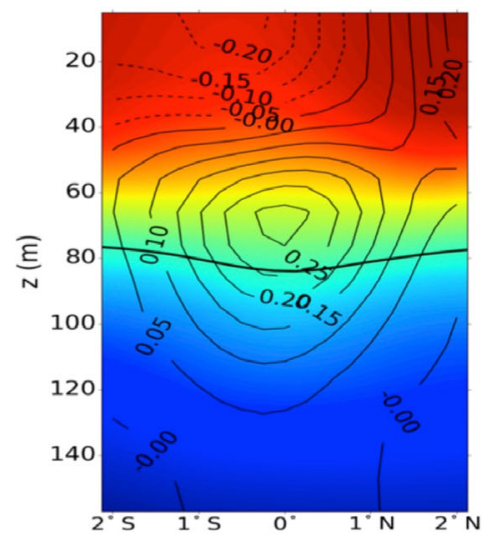

(d)

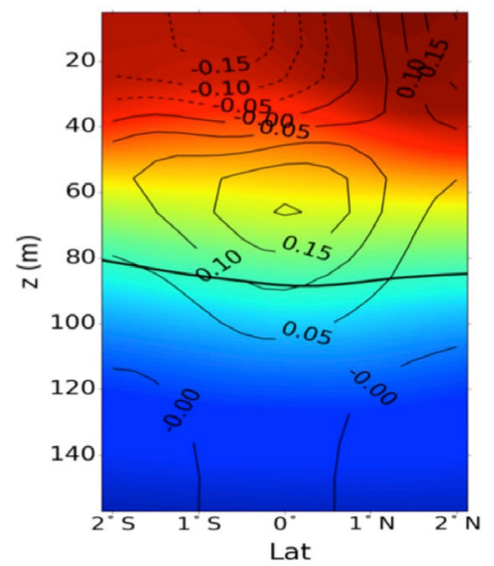

(b)

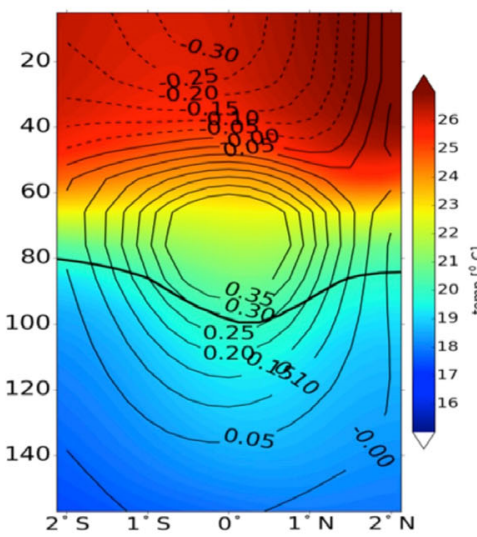

(e)

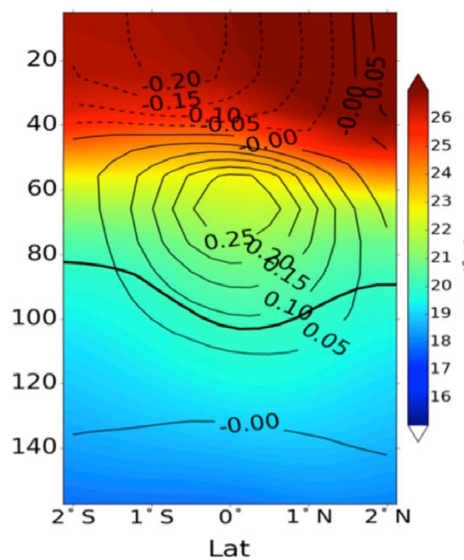

(c)

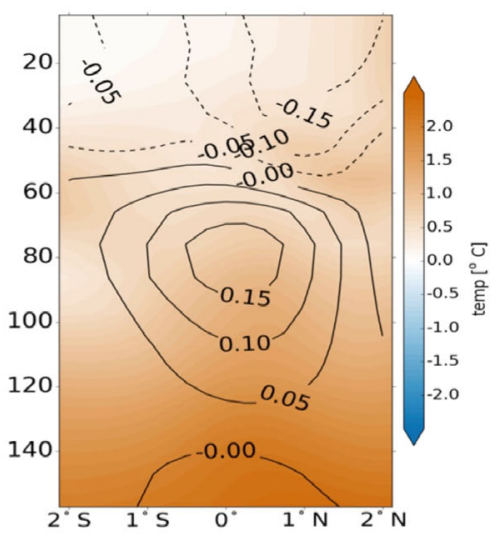

(f)

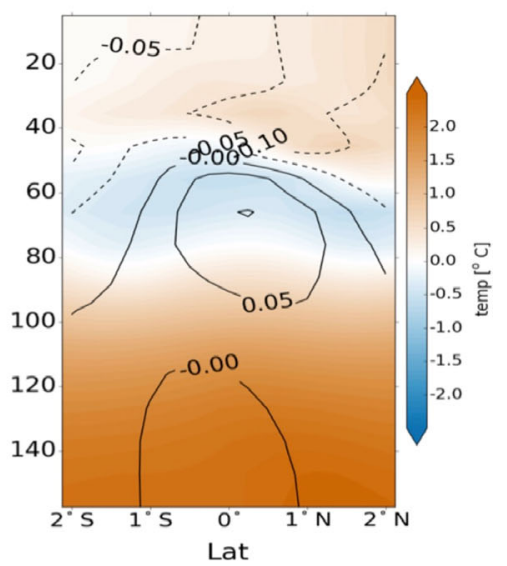

Fig. 11 Latitude-depth diagrams of temperature (Celsius, shading) and zonal currents $\left(\mathrm{m} \mathrm{s}^{-1}\right.$, contours) at longitude $10^{\circ} \mathrm{W}$ for a CTRL, b NCCS experiments, and $\mathbf{c}$ the difference between them, and at longitude $0^{\circ} \mathrm{E}$ for $\mathbf{d}$ CTRL, e NCCS, and $\mathbf{f}$ the respective difference. The thicker black line in $\mathbf{a}, \mathbf{b}, \mathbf{d}$, and $\mathbf{e}$ represents the $20^{\circ} \mathrm{C}$ isotherm 
surface cooling, is affected, contributing to the warm bias observed in the eastern part of the equatorial Atlantic. As seen in Fig. 11 , at $10^{\circ} \mathrm{W}$, the EUC core, simulated by CTRL (Fig. 11a) and NCCS (Fig. 11b) experiments, lies on the thermocline. The magnitude is stronger for NCCS experiment, with maximum values around $0.35 \mathrm{~m} \mathrm{~s}^{-1}$, i.e., about $0.15 \mathrm{~m} \mathrm{~s}^{-1}$ higher than CTRL experiment (Fig. 11c). At $0^{\circ}$ $\mathrm{E}$, the EUC core still lies on the thermocline, with weaker maximum magnitudes, around 0.20 and $0.25 \mathrm{~m} \mathrm{~s}^{-1}$ for the CTRL and NCCS experiments, respectively (Fig. 11d, e), indicating that the difference between the EUC cores maximum is smaller, about $0.05 \mathrm{~m} \mathrm{~s}^{-1}$ (Fig. 11f). The results obtained by Johns et al. (2014), based on ADCP data, show that the EUC core at $0^{\circ} \mathrm{E}$ is in fact weaker than at $10^{\circ} \mathrm{W}$. But, the values reduce from about 0.6 to $0.5 \mathrm{~m} \mathrm{~s}^{-1}$, both much stronger than the ones obtained by both BESM experiments, possibly contributing to the detected temperature biases of the BESM results described before, in accordance to Johns et al. (2014) explanation.

Nonetheless, the results shown in this article represent a step forward in relation to the previous version of the BESM, firstly introduced to the CMIP community in Nobre et al. (2013). Additional improvements such as the inclusion of a land-surface model with dynamic vegetation and surface hydrology are currently in progress. They are part of an ongoing effort to build an Earth System Model in Brazil, aimed at improving our knowledge about ocean and atmospheric coupled variability over the Tropical Atlantic.

\begin{abstract}
Acknowledgments The authors would like to thank the editor and anonymous reviewers for their constructive comments, which helped sharpen this study results. Rede CLIMA, FAPESP and INPE are acknowledged for the use of its supercomputer facility, which made this research possible. This research was partially funded by $\mathrm{CNPq}$ through grants IBAS/MOST No. 490237/2011-8 and INCT-MC No 573747/ 2008-0.
\end{abstract}

Open Access This article is distributed under the terms of the Creative Commons Attribution 4.0 International License (http://creativecommons. org/licenses/by/4.0/), which permits unrestricted use, distribution, and reproduction in any medium, provided you give appropriate credit to the original author(s) and the source, provide a link to the Creative Commons license, and indicate if changes were made.

\section{References}

Anthes RAA (1977) Cumulus parameterization scheme utilizing a onedimensional cloud mode. Mon Weather Rev 105:270-286. doi:10. 1175/1520-0493(1977)105<0270:ACPSUA >2.0.CO;2

Bottino MJ (2013) Impacto da parametrização de propriedades de nuvens na simulação do clima na região do Atlântico com o modelo acoplado oceano-atmosfera de INPE/CPTEC. Ph.D. Thesis (in portuguese), Instituto Nacional de Pesquisas Espaciais (INPE), Brazil, 124 pp., (sid.inpe.br/mtc-m19/2013/04.29.01.35-TDI), http://urlib. net/8JMKD3MGP7W/3E2L5B5
Bottino MJ, Nobre P (2015) Impacts of cloud cover schemes on the Atlantic climate in a coupled ocean-atmosphere model simulation (to be submitted to Climate Dynamics)

Bourlès B et al (2008) The Pirata Program: history, accomplishments, and future directions. Bull Am Meteorol Soc 89:1111-1125. doi:10. 1175/2008BAMS2462.1

Cavalcanti IFA, Marengo JA, Satyamurty P, Nobre CA, Trosnikov I, Bonatti JP et al (2002) Global climatological features in a simulation using CPTEC/COLA AGCM. J Clim 15:2965-2988. doi:10.1175/ 1520-0442(2002)015<2965:GCFIAS > 2.0.CO;2

Chou MD, Suarez MJ (1999) A solar radiation parameterization (CLIRAD-SW) developed at Goddard Climate and Radiation Branch for Atmospheric Studies, Goddard Space Flight Center, Greenbelt, NASA Tech. Memo., NASA/TM-1999-104606(15), 40 p

Collins WD, et al (2004) Description of the NCAR Community Atmosphere Model (CAM3). Tech. Rep. NCAR/TN-464STR, National Center for Atmospheric Research, Boulder, CO, $226 \mathrm{p}$

Giarolla E, Nobre P, Malagutti M, Pezzi LPP (2005) The Atlantic Equatorial Undercurrent: PIRATA observations and simulations with GFDL Modular Ocean Model at CPTEC. Geophysical Research Letters 32, L10617. doi: 10.1029/2004GL022206

Grell GA, Devenyi D (2002) A generalized approach to parameterizing convection combining ensemble and data assimilation techniques. Geophys Res Lett 29:38-1-38-4. doi:10.1029/2002GL015311

Griffies SM (2009) Elements of MOM4p1. GFDL Ocean Group Tech. Rep., 6, 444 pp

Griffies SM et al (2009) Coordinated ocean-ice reference experiments (COREs). Ocean Model 26:1-46. doi:10.1016/j.ocemod.2008.08. 007

Harshvardhan R, Corsetti TG (1984) Longwave radiation parameterization for the UCLA/GLAS GCM. NASA Technical Memorandum $86072,65 \mathrm{p}$

Harshvardhan R, Randall DA, Corsetti TG (1987) A fast radiation parameterization for general circulation models. J Geophys Res 92: $1009-1016$

Izumo T (2005) The equatorial undercurrent, meridional overturning circulation, and their roles in mass and heat exchanges during El Nino events in the tropical Pacific ocean. Ocean Dyn 55:110-123. doi:10. 1007/s10236-005-0115-1

Johns WE, Brandt P, Bourlès B, Tantet A, Papapostolou A, Houk A (2014) Zonal structure and seasonal variability of the Atlantic Equatorial Undercurrent. Clim Dyn. doi:10.1007/s00382-0142136-2, Online First (04/2014)

Kalnay EM et al (1996) The NCEP/NCAR 40-Year Reanalysis Project. Bull Am Meteorol Soc 77:437-471. doi:10.1175/1520-0477(1996) 077<0437:TNYRP $>2.0 . \mathrm{CO} ; 2$

Kiehl JT et al (1996) Description of the NCAR Community Climate Model (CCM3). NCAR Tech. Note NCAR/TN-420+STR, 143 p

Kiehl JT et al (1998) The National Center for Atmospheric Research Community Climate Model: CCM3. J Clim 11:1131-1149

Kinter JL III et al (1997) The COLA atmosphere-biosphere general circulation model. Vol. 1: Formulation. Rep. 51. COLA, Calverton, $46 \mathrm{p}$

Large WG, Yeager SG (2009) The global climatology of an interannually varying air-sea flux data set. Clim Dyn 33:341-364

Levitus S, Boyer T (1994) World Ocean Atlas 1994, Vol. 4: Temperature. NOAA Atlas NESDIS 4, U.S. Gov. Printing Office, Wash., D.C., $117 \mathrm{p}$

Liebmann B, Smith CA (1996) Description of a complete (interpolated) outgoing longwave radiation dataset. Bull Am Meteorol Soc 77: 1275-1277

Locarnini RA, Mishonov AV, Antonov JJ, Boyer TP, Garcia HE, Baranova OK et al (2010) World ocean atlas 2009, volume 1: temperature. In: Levitus S (ed) NOAA Atlas NESDIS 68. U.S. Government Printing Office, Washington, $184 \mathrm{p}$ 
Mellor GL, Yamada T (1982) Development of a turbulence closure model for geophysical fluid problems. Rev Geophys Space Phys 20:851875

Nobre P, de Almeida RAF, Malagutti M, Giarolla E (2012) Coupled ocean-atmosphere variations over the South Atlantic Ocean. J Clim 25:6349-6358. doi:10.1175/JCLI-D-11-00444.1

Nobre P et al (2013) Climate simulation and change in the Brazilian climate model. J Clim 26(17):6716-6732. doi:10.1175/JCLI-D-1200580.1

Richter I, Xie S-P (2008) On the origin of equatorial Atlantic biases in coupled general circulation models. Clim Dyn 31:587-598. doi:10. 1007/s00382-012-1624-5

Richter I, Xie S-P, Behera SK, Doi T, Masumoto Y (2012) Equatorial Atlantic variability and its relation to mean state biases in CMIP5. Clim Dyn 42:171-188. doi:10.1007/s00382-012-1624-5

Slingo JM (1987) The development and verification of a cloud prediction scheme for the ECMWF model. Q J R Meteorol Soc 113:899-927

Smith TM, Reynolds RW, Peterson TC, Lawrimore J (2008) Improvements NOAAs historical merged land-ocean temp analysis (1880-2006). J Clim 21:2283-2296

Stocker T et al (2013) Climate Change 2013: The Physical Science Basis. Contribution of Working Group I to the Fifth Assessment Report of the Intergovernmental Panel on Climate Change, Cambridge
University Press, Cambridge, United Kingdom and New York, NY, USA. http://www.climatechange2013.org/images/report/ WG1AR5 TS FINAL.pdf

Tarasova TA, Barbosa HMJ, Figueroa SN (2006) Incorporation of new solar radiation scheme into CPTEC GCM. Tech. Rep. INPE-14052NTE/371, Instituto Nacional de Pesquisas Espaciais, Brazil, 53 p

Tiedtke M (1984) The sensitivity of the time mean large-scale flow to cumulus convection in the ECMWF model. Workshop on convection in large-scale numerical models.. Shinfield Park, Reading, United Kingdom, ECMWF, 297- 316

Wang B, Ding Q, Fu X, Kang I-S, Jin K, Shukla J et al (2005) Fundamental challenge in simulation and prediction of summer monsoon rainfall. Geophys Res Lett 32, L15711. doi:10.1029/ 2005GL022734

Winton M (2000) A reformulated three-layer sea ice model. J Atmos Ocean Technol 17:525-531

Xue Y, Sellers PJ, Kinter JL III, Shukla J (1991) A simplified biosphere model for global climate studies. J Clim 4:345-364

Yang H, Wang F (2009) Revisiting the thermocline depth in the Equatorial Pacific. J Clim 22:3856-3863. doi:10.1175/ 2009JCLI2836.1

Yin FL, Sarachik ES (1993) Dynamics and heat balance of steady equatorial undercurrents. J Phys Oceanogr 23:1647-1669 